Journal of Clinical Investigation

Vol. 43, No. 7, 1964

\title{
Mineral Analysis of the Fourth Lumbar Vertebra in Health and Renal Failure*
}

\author{
Michael Kaye with the technical assistance of T. Thibault \\ (From the Renal Service, Department of Medicine, Queen Mary Veterans' Hospital, and the \\ Department of Medicine, the Montreal General Hospital, Montreal, Canada)
}

In a previous study of osteosclerosis in chronic renal failure (1), it was noted that this type of bone disease is characteristically seen when renal failure has been present for several years. We wished to confirm that the duration of renal disease is related to the changes in the skeleton and that the radiological appearance is due to an increase in mineral content of the bone and to see whether the calcium and phosphorus are present in the same proportions as are found in healthy individuals. Earlier papers dealing with bone analysis have used weight as the reference standard, but because change in the quantity of normal bone will give unaltered values, volume is $\checkmark$ a more meaningful reference $(2,3)$.

As any change in the mineral content of the skeleton is spread over such a large mass, sampling an area where small changes might be detected early was necessary. Cancellous trabecular bone is metabolically much more active in the adult than is cortical bone, and the sites of most rapid turnover after cessation of growth are the vertebrae, sternum, and ribs (4-6). For this reason and because osteosclerosis is first visible radiologically in the lumbar spine $(1,7)$, the fourth lumbar vertebra was chosen for analysis. No previous data are available for comparison with the present series for bone analyses in renal disease. However, in a comparable study of the calcium content from a $1-\mathrm{cm}$ slab of the fourth lumbar vertebra in routine autopsies, Caldwell and Collins (3) found values of 1.85 and 1.72 moles per $\mathrm{L}$ of calcium in males and females, respectively, when cases with osteoporosis were excluded. These values are close to our normal mean of 1.93 moles per $L$ for the whole vertebra, which probably included more compact bone. The vertebral body was removed at the junction of

* Submitted for publication October 14, 1963 ; accepted February 26, 1964. the pedicles and the body; as the bone was not complete and differed in size among the various subjects, a unit volume reference standard of $1 \mathrm{~L}$ was used in all cases. The full thickness of the bone from one articular margin to the next was, however, included in the specimen.

\section{Methods}

The control subjects were a selected group who were well nourished at the time of death, did not have metastatic cancer, and had histologically normal vertebra adjacent to the one taken for analysis. The patients with renal failure were a consecutive series of unselected subjects most of whom had died from uremia or its complications; patients with cancer of the urinary tract were not included. They were subdivided according to the known minimal duration of renal failure. Those with acute renal failure were oliguric, and those with chronic renal failure had blood urea nitrogen levels of $25 \mathrm{mg}$ per $100 \mathrm{ml}$ or above (normal, 10 to 20 $\mathrm{mg}$ per $100 \mathrm{ml}$ ). The biochemical findings in these patients are summarized in Table I from values obtained before death. The interval between the date of the findings and death varied from a day to as long as 1 month in some of the patients with chronic renal failure, but in the majority death was within 1 week.

The bone with adherent muscle, periosteum, etc., was wrapped in aluminum foil, placed in a sealed glass jar, and stored at $-20^{\circ} \mathrm{C}$ till analyzed. It was then thawed in the refrigerator and trimmed of all nonosseous tissues. The trimming was carried out in a plastic bag maintained at $100 \%$ humidity. The sample was weighed in air and weighed again submerged in water. After correction for the water temperature, the difference represented the volume of the bone. Experimental determination of the volume of a metal cylinder of similar volume and weight as the bones gave determined values of $100.05 \%$ of the expected. In a series of preliminary experiments, the effect of coating the bone in wax before weighing in water and also uptake of water by the bone were studied. We found that there was no change in determined volume of the bone consequent to its immersion in water for the few minutes required for weighing. The vertebra was then sawed into small fragments and dried to constant weight at $100^{\circ} \mathrm{C}$. The pieces of dry bone were defatted using a Soxhlet ap- 
TABLE I

Biochemical values of patients shortly before death

\begin{tabular}{|c|c|c|c|c|c|}
\hline Group & $\begin{array}{c}\text { Duration of renal } \\
\text { failure }\end{array}$ & BUN* & Calcium & Phosphorus & Bicarbonate \\
\hline & & $\mathrm{mg} / 100 \mathrm{ml}$ & $\mathrm{mg} / 100 \mathrm{ml}$ & $\mathrm{mg} / 100 \mathrm{ml}$ & $m E q / L$ \\
\hline $\begin{array}{l}\text { 2. Mean } \\
\text { Range } \\
\text { No. = } 11\end{array}$ & $<3 \mathrm{mos}$ & $\begin{array}{c}132 \\
38-204\end{array}$ & $\begin{array}{c}7.3 \\
6.6-8.5\end{array}$ & $\begin{array}{c}10.5 \dagger \\
4-14.6\end{array}$ & $\begin{array}{l}19.2 \\
4-28\end{array}$ \\
\hline $\begin{array}{l}\text { 3. Mean } \\
\text { Range } \\
\text { No. = } 13\end{array}$ & $>3 \operatorname{mos}<1 \mathrm{yr}$ & $\begin{array}{c}170 \\
100-276\end{array}$ & $\begin{array}{c}7.7 \\
5.8-8.9\end{array}$ & $\begin{array}{l}10.2 \\
5.4-16.0\end{array}$ & $\begin{array}{l}18.9 \\
5-30\end{array}$ \\
\hline $\begin{array}{l}\text { 4. Mean } \\
\text { Range } \\
\text { No. = } 11\end{array}$ & $>1 \mathrm{yr} \quad<4 \mathrm{yrs}$ & $\begin{array}{c}168 \\
83-268\end{array}$ & $\begin{array}{c}6.89 \\
4.7-9.7\end{array}$ & $\begin{array}{c}8.84 \\
5.5-14.5\end{array}$ & $\begin{array}{l}14.7 \\
4-24\end{array}$ \\
\hline $\begin{array}{l}\text { 5. Mean } \\
\text { Range } \\
\text { No. }=5\end{array}$ & $6-14$ yrs & $\begin{array}{c}167 \\
90-240\end{array}$ & $\begin{array}{c}7.96 \\
5.7-10.5\end{array}$ & $\begin{array}{c}8.9 \\
4.9-14.2\end{array}$ & $\begin{array}{c}18.2 \\
8.9-25\end{array}$ \\
\hline
\end{tabular}

* BUN = blood urea nitrogen.

$\dagger$ Determinations available for only 3 patients.

paratus and refluxing for 6 hours with ethyl ether and 6 hours with petroleum ether. After reweighing, the bone was ground with a Wiley mill to pass through a 20 -mesh screen, thoroughly mixed, and $0.2-$ to $0.5-\mathrm{g}$ samples were ashed in a muffle furnace at $600^{\circ} \mathrm{C}$ overnight. The dissolved ash was used for phosphorus determinations by the method of Fiske and SubbaRow (8) and for calcium by oxalate precipitation and permanganate titration (9). The dry, ground, defatted bone was analyzed for nitrogen by the micro-Kjeldahl technique (10). Recoveries for calcium, phosphorus, and nitrogen were in the range of $98.8 \%$ to $101 \%$ on repeated determinations.

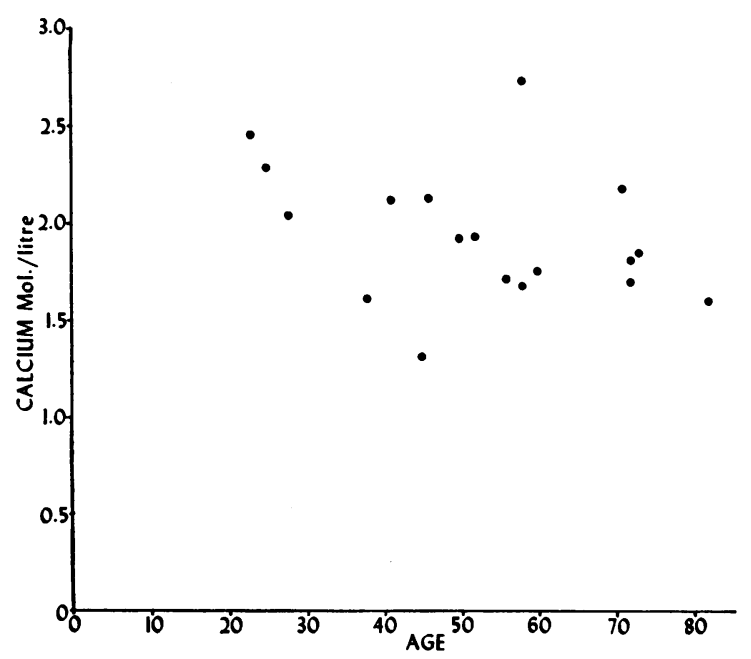

Fig. 1. Control group showing No Change in Calcium WITH INCREASING AGE.

\section{Results}

No obvious effect of age upon bone mineral was seen in the control group (Figure 1). This is likely due to exclusion of patients with osteoporosis and malnutrition and some selection so that most subjects were between 40 and 70 years of age to match those with renal disease. Except for their kidney disease, patients in the acute renal failure group (2) were unselected and might be considered a more valid control for those having prolonged renal failure if acute renal failure is assumed not to change the mineral content of the bone. Although this appears likely, it cannot be proven and consequently both groups 1 and 2 (Table II) have been used for comparison with the other groups. There were only 13 bones from females out of the 58 bones analyzed, and with one exception the values were all close to the means and will not be considered separately.

The results for calcium, phosphorus, and nitrogen per liter of bone showed a steady rise as the duration of renal failure increased and were highest in those who had been azotemic more than 4 years (group 5). Significant differences between the means by $t$ tests were present between groups 1 or 2 , and 4 and 5 (Table III), and the alterations in mineral composition were also reflected in a rise in the density of the fresh bone. Results per kilogram fat free dry bone are of interest, as there was no change in calcium but a 
VERTEBRAL ANALYSIS IN HEALTH AND RENAL FAILURE

1369

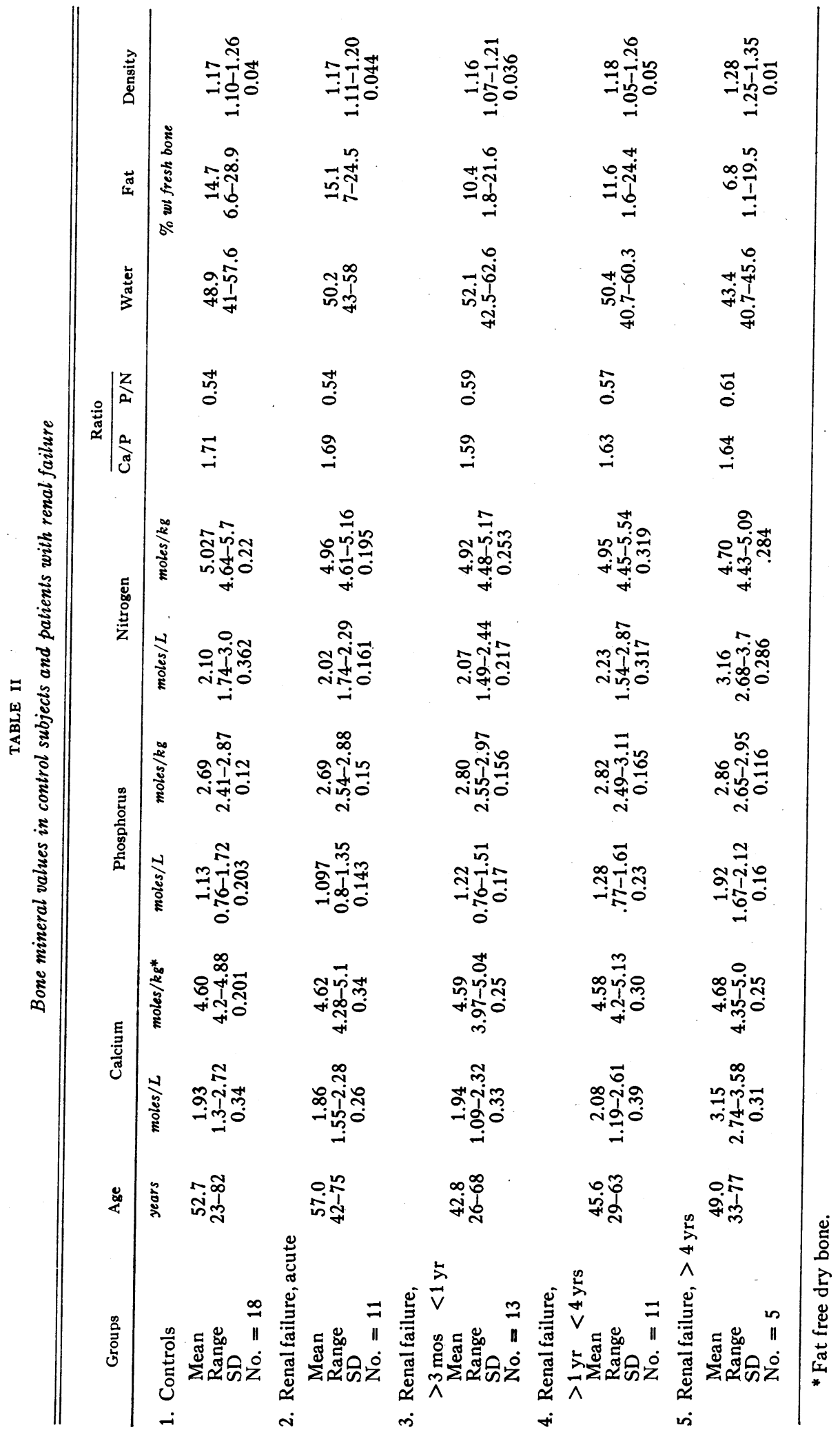


TABLE III

$t$ tests between means of different groups

\begin{tabular}{|c|c|c|c|c|c|c|c|c|c|}
\hline \multirow[b]{2}{*}{ Groups* } & \multirow{2}{*}{\multicolumn{2}{|c|}{ Calcium }} & \multirow{2}{*}{\multicolumn{2}{|c|}{ Phosphorus }} & \multirow{2}{*}{\multicolumn{2}{|c|}{ Nitrogen }} & \multicolumn{2}{|c|}{ Ratio } & \multirow{3}{*}{ Density } \\
\hline & & & & & & & \multirow[t]{2}{*}{$\mathrm{P} / \mathrm{N}$} & \multirow[t]{2}{*}{$\mathrm{Ca} / \mathrm{P}$} & \\
\hline & moles $/ L$ & moles/kg & moles $/ L$ & moles $/ \mathrm{kg}$ & moles $/ L$ & moles $/ \mathrm{kg}$ & & & \\
\hline $\begin{array}{l}1-3 \\
1-4\end{array}$ & $\begin{array}{l}<0.90 \\
<0.30\end{array}$ & & $\begin{array}{l}<0.30 \\
<0.20\end{array}$ & $\begin{array}{l}<0.025 \\
<0.02\end{array}$ & $\begin{array}{l}<0.80 \\
<0.40\end{array}$ & & $\begin{array}{l}<0.05 \\
<0.10\end{array}$ & $\begin{array}{l}<0.05 \\
<0.025\end{array}$ & \\
\hline $1-5$ & $<0.001$ & & $<0.001$ & $<0.02$ & $<0.001$ & $<0.02$ & $<0.005$ & $<0.20$ & $<0.001$ \\
\hline $2-3$ & $<0.60$ & & $<0.20$ & $<0.05$ & $<0.60$ & & $<0.20$ & $<0.05$ & \\
\hline $2-4$ & $<0.20$ & & $<0.05$ & $<0.05$ & $<0.10$ & & & $<0.05$ & \\
\hline $2-5$ & $<0.001$ & & $<0.001$ & $<0.05$ & $<0.001$ & $<0.10$ & $<0.05$ & $<0.20$ & $<0.001$ \\
\hline $3-4$ & $<0.40$ & & $<0.50$ & $<0.60$ & $<0.20$ & & & & \\
\hline $3-5$ & $<0.001$ & & $<0.001$ & $<0.40$ & $<0.001$ & $<0.20$ & $<0.20$ & & $<0.001$ \\
\hline $4-5$ & $<0.001$ & & $<0.001$ & $<0.50$ & $<0.001$ & $<0.20$ & $<0.30$ & & $<0.02$ \\
\hline
\end{tabular}

$* 1=$ control; $2=$ acute renal failure, $<3$ months; $3=$ renal failure $>3$ months $<1$ year; $4=$ renal failure $>1$ year $<4$ years; $5=$ renal failure $>4$ years.

significant rise in the phosphorus and a less marked fall in the nitrogen content. This was shown in the $\mathrm{P}: \mathrm{N}$ ratio, which changed from 0.54 in the control subjects to 0.61 when renal failure had been present more than 4 years. The $\mathrm{Ca}: \mathrm{P}$ ratio also changed due to the increase in the phosphorus content.

\section{Discussion}

The results of this study suggest a progressive storage of mineral in the fourth lumbar vertebra of adult patients with renal failure. This is a gradual process taking place slowly over many years. No children or adolescents have been included in this study; the conclusions reached cannot, therefore, be applied to the bones during the growth period, when the calcium requirements are so much greater and demineralization would be more likely to occur.

Alteration was found during the course of renal failure in the molar proportions of calcium, phosphorus, and nitrogen. Unlike the values per liter of bone, however, the change in the phosphorus content per kilogram showed very little further increase after 1 year of renal failure. Although this change could have been due to the elevated extracellular phosphorus at the time of death, the normal phosphorus content of the bone in the acute renal failure group would be against this explanation. The $\mathrm{Ca}: \mathrm{P}$ ratio of 1.71 for the controls is very similar to the theoretic 1.67 for hydroxyapatite (11), and the fall to 1.59 to 1.64 with renal failure of more than 3 months' duration suggests more phosphorus associated with the bone crystal, possibly due to the higher extracellular phosphorus at the time of bone formation. As the serum phosphorus shows little change till renal function is severely compromised late in the course of renal failure, a progressive change with time in the $\mathrm{Ca}: \mathrm{P}$ ratio might not be seen, and the altered bone composition would only appear within the last few months of life. This is in contrast to the steady increase in mineral per unit volume already described.

Whether the same change is taking place in other bones cannot be answered from this study. Although changes of osteosclerosis are detected first in the lumbar vertebrae, they eventually are seen elsewhere if the patient survives long enough $(1,7)$. The change in the vertebrae has been suggested to result from the transfer of calcium to the spine from the long bones, but there is usually no evidence of demineralization in the long bones, sometimes the reverse, and this would require one part of the skeleton to react differently from another part in response to what is probably a general metabolic change. We think this unlikely and would interpret the present data as indicating a generalized increase in body bone mass that is apparent first in those areas with the most active turnover.

Review of the patients in group 5 with the most marked increase in mineral content failed to show any special distinguishing features except 
for the length of documented azotemia. Three of the five in this group were included in a previous report (1) (as F.D., E.J., and J.L.), and the other two were in no way dissimilar. Radiological examination showed vertebral osteosclerosis in three of these patients, and at autopsy all five showed histological osteosclerosis. In one case this was combined with osteitis fibrosa and in another with osteomalacia. Review of the lumbar vertebrae by $\mathrm{X}$ ray during life had shown normal contour in all instances.

Characterization of the reasons for the increase in bone found in this study can come only through a kinetic investigation of mineral metabolism in different stages of renal failure. The data obtained in a separate study suggest that the basic abnormality lies in decreased bone resorption (12).

\section{Summary}

Analyses of the fourth lumbar vertebra have been carried out in 18 control subjects and 40 patients with renal failure varying in duration from 1 week to over 15 years. A rise in the calcium, phosphorus, and nitrogen content of the bone was demonstrated when renal failure had persisted for a sufficient length of time. We suggest that these findings are compatible with an over-all increase in bone mineral content varying in degree from one site to another, depending on turnover rates in different bones, duration and severity of renal failure, and the superaddition of osteitis fibrosa or osteomalacia or both. After 3 months of renal failure the proportion of phosphorus in the vertebra increased, possibly reflecting the higher serum phosphorus at the time of bone formation.

\section{Acknowledgments}

We wish to thank Dr. W. H. Mathews, Pathologist-inChief, Montreal General Hospital, for his assistance in obtaining many of the bones used in this study, and Dr. $\mathrm{W}$. Light for his review of the $\mathrm{X}$ rays.

\section{References}

1. Kaye, M., J. E. Pritchard, G. W. Halpenny, and W. Light. Bone disease in chronic renal failure with particular reference to osteosclerosis. Medicine (Baltimore) 1960, 39, 157.

2. Robinson, R. A., and S. R. Elliott. The water content of bone. 1. The mass of water, inorganic crystals, organic matrix, and " $\mathrm{CO}_{2}$ space" components in a unit volume of dog bone. J. Bone Jt Surg. 1957, 39A, 167.

3. Caldwell, R. A., and D. H. Collins. Assessment of vertebral osteoporosis by radiographic and chemical methods postmortem. J. Bone Jt Surg. 1961, 43B, 346.

4. Kulp, J. L., W. R. Eckelmann, and A. R. Schulert. Strontium-90 in man. Science 1957, 125, 219.

5. Trotter, M., and R. R. Peterson. The relationship of ash weight and organic weight of human skeletons. J. Bone Jt Surg. 1962, 44A, 669.

6. Assay of strontium-90 in human bone in the United Kingdom, results for 1962, part I, with some further results for 1961. Spec. Rep. Ser. med. Res. Coun. (Lond.) 1963, no. 6.

7. Zimmerman, H. B. Osteosclerosis in chronic renal disease. Amer. J. Roentgenol. 1962, 88, 1152.

8. Fiske, C. H., and Y. SubbaRow. The colorimetric determination of phosphorus. J. biol. Chem. 1925, 66, 375.

9. Hawk, P. B., B. L. Oser, and W. H. Summerson. Practical Physiological Chemistry. New York, McGraw-Hill, 1954, p. 962.

10. Varley, H. Practical Clinical Biochemistry, 3rd ed. London, Heinemann, 1962.

11. Neuman, W. F., and M. W. Neuman. The Chemical Dynamics of Bone Mineral. Chicago, University of Chicago Press, 1958.

12. Kaye, M., and M. Silverman. In preparation. 